\title{
The Design of Dormitory Management System for College Students Based on Android Platform
}

\author{
Manman PENG ${ }^{1, a}$, Xinni XIE ${ }^{2}$ \\ ${ }^{1}$ Hunan University, Changsha 410082, China \\ ${ }^{2}$ Guangdong Peizheng College, Guangzhou 510830,China \\ amanmanpeng@126.com
}

Keywords: Android Platform; College Students; Dormitory Management System

\begin{abstract}
The students' dormitory is the main place to college students' daily life, so the students' dormitory management is an important part of school management. As the growth of the school recruitment of students scale, the growing number of students, make the student dormitory management faced with multiple, complex, complex situation. The problem of how to decipher, become the focus of the school logistics department leadership focus on. In order to adapt to the needs of the development of the school, and further improve the efficiency of school logistics work, school logistics department need a adapt to student dormitory daily management software system, in order to give full play to the advantages of modern information technology and Internet, realize the artificial management to change the way of computer management, increases the working efficiency of the dormitory management.
\end{abstract}

\section{Introduction}

In recent years, along with the rapid development of higher vocational education in our country, the higher vocational colleges are doing a lot of enrollment expansion, new with this kind of situation, the school dormitory management is becoming more and more heavy burden. School is hard to come by every student dormitory, under the condition of more cannot be targeted to the students' dormitory management and guidance [1]. And with the rapid development of computer software technology and Internet technology, school of digital campus network gradually thorough, the student dormitory management information system based on intelligent data acquisition of construction has become a pressing need of high vocational colleges [3].

This design to study the student dormitory management work process, in order to improve the student's dormitory management efficiency, improve students, dormitory administrators, and school staff dormitory management satisfaction, through the analysis and research of the student's dormitory management workflow, combined with the current school of digital campus network advantages, based on the Android on the basis of the research and development of the intelligent information management system of the student's dormitory. The whole system including the administrator information management platform, students' dormitory information management platform, the dormitory administrator information management platform of three parts, each part respectively have their own different function.

\section{Android mobile development technology}

The Android platform released by Google is an open source operating system based on the Linux kernel, due to its characteristics of openness, easy operation, widely used in intelligent mobile phone, tablet computer and other mobile devices. Open Android system mobile phone company and leader of the alliance and the development of. The Android platform's openness means that the mobile terminal equipment manufacturers almost all can be added to the Android Development League application software [3]. The opening of this platform means that applications to encourage developers to develop more complex to some extent, in order to attract more users choose to use Android mobile intelligent terminal equipment. Android has become the most popular intelligent 
terminal platform, so the choice of Android platform "mobile learning" development is the proper selection [4].

According to the characteristics of mobile learning fully considered, and the user needs the guarantee, mobile Android based learning system will be the mobile learning system design of the main client and the mobile learning system based on the two part of servers. The overall system architecture as shown in Figure 1, the system will be based on the Android support online or offline learning network by 3G and WIFI connection.

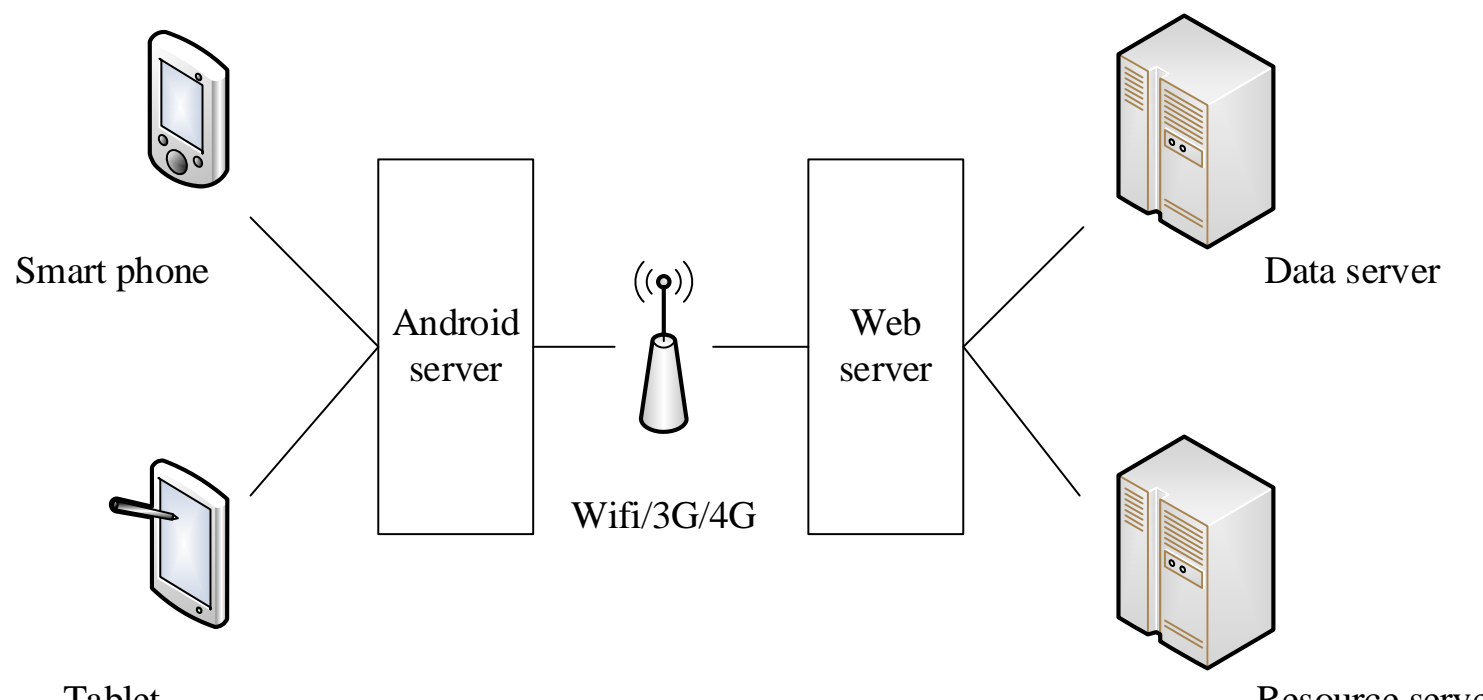

Figure 1. Mobile learning system framework based on the Android platform

Mobile learning system to customers include portable equipment Android intelligent mobile phone and Android tablet computer, the user through a mobile device to access their learning and other learning courses and related operation [5]. Mobile learning system server mainly consists of two parts, the database server and server resources. The main function of the database server is to store relevant to students' personal information, legitimacy and is responsible for the correctness verification and feedback of the users to submit personal information. Server management curriculum resources and processing online interactive information, including the student asked the teacher to answer questions.

\section{System function requirement analysis}

Through the control of the server database and management, this system can realize the building management, room management, dormitory management, user management, rights management, electricity management, dormitory distribution, dormitory health appraisal required functions, such as system operation is simple, friendly man-machine interface, stable operation. Intelligent student dormitory management information system are introduced in detail in this paper the whole process of research and development, this paper expounds the software development process is applied to a variety of techniques and methods, mainly completed the intelligent student dormitory management information system requirements analysis, system design, database design, system development and testing, etc. Student's dormitory information management system can solve the school every year, the problem of student dormitory management, to standardize the management of the students' dormitory process, reduce the staff dormitory management, dormitory administrators and students' labor intensity, improve work efficiency. Through detailed investigation and research of the school dormitory management, drawing out of the students. 


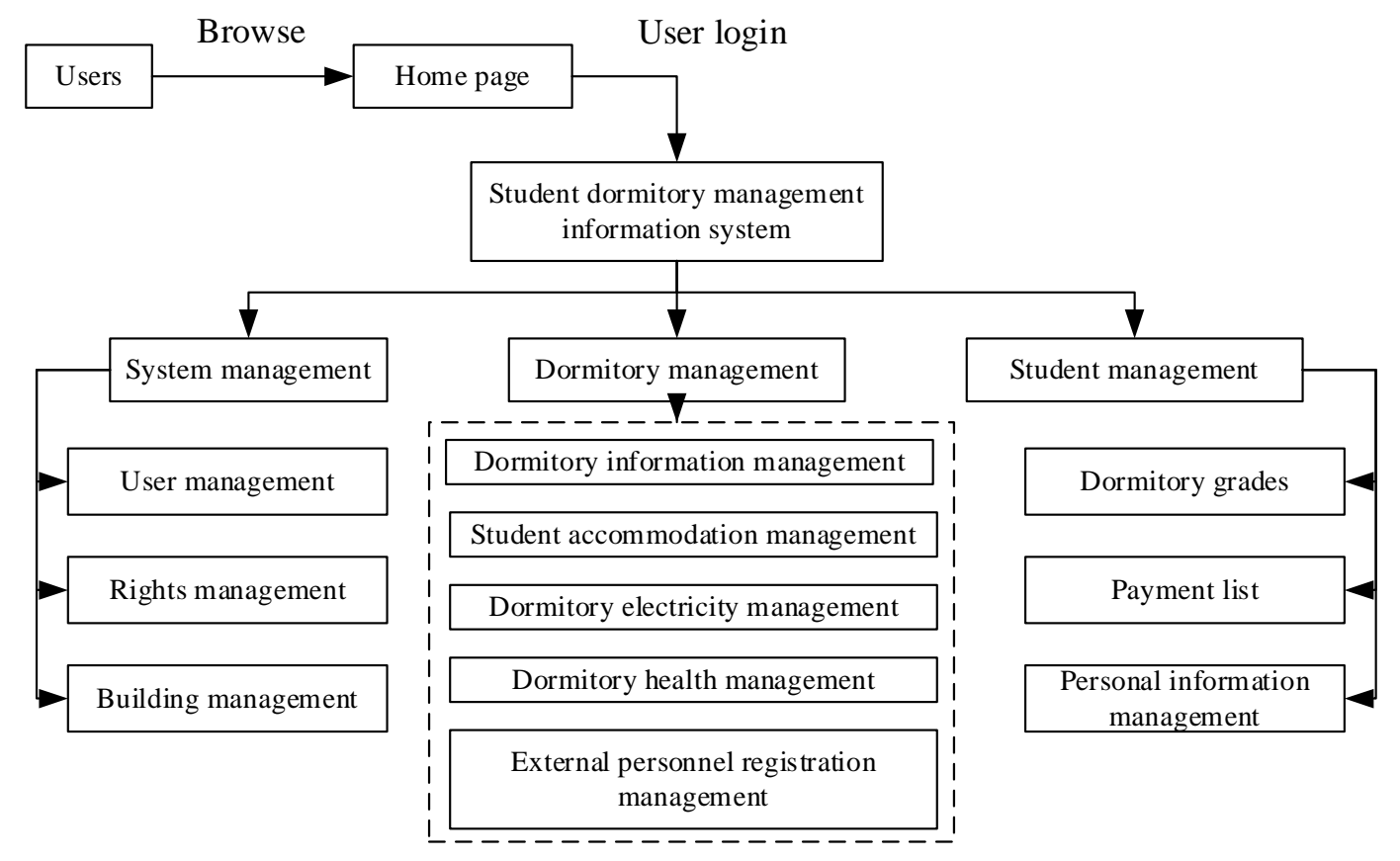

Figure 2. Function requirement of the dormitory management system for college students

The basic reasonable structure design, function relatively complete, its operation is stable, after the system test to meet the needs of the college student dormitory management work. This system is able to timely collect detailed information to the students' dormitory, can accurately and efficiently statistics student dormitory accommodation, student dormitory electricity situation, the students' dormitory health situation and foreign personnel in and out of the data, make the students' dormitory work management personnel can real-time understanding of students' dormitory information in detail, and according to the data to adjust the students' dormitory management strategy, so as to effectively solve the problem of asymmetric information, for the majority of students to provide a good service platform.

\section{College student dormitory management system design based on Android}

Using the computer and network information means such as students' dormitory management has become the inevitable trend. With the continuous optimization of mobile network and the expansion of the wireless communication technology, the student apartment management by $3 \mathrm{~g}$ wireless mobile terminals, office whenever and wherever possible. The advantage of the Android platform combining with the characteristics of mobile portable and powerful function, its use in the management of student apartment can not only solve the current information system is confined to limited transmission and people going out in the outside network information, more able to develop a variety of functions on the platform, meet the demand of management. From the practice of the school dormitory management, this paper is based on the Android platform, the university students' dormitory management system based on Android framework is shown in figure 3.

This system according to user needs the student dormitory management information system is divided into seven function modules, namely: system management module, the student accommodation module, dormitory management module, health check module, water and electricity charge module registration module, housing repair service module, the migrant population. Among them, the system management module is divided into two sub-modules user registration, password modification. Dormitory management module includes add, query the dormitory. Students check module includes: hotel management, student information query. Health check module includes add inspection information and inspection information query two parts. University student's dormitory information management system to students, dormitory and 
management of each entity major data and information through a database system to add, modify, and delete etc., to maintain the current of the student dormitory management information system. Through the development of student apartment system based on Android system, meet the requirements of the school management work, and at the same time also for the $3 \mathrm{~g}$ era school apartment informatization construction provides the reference.

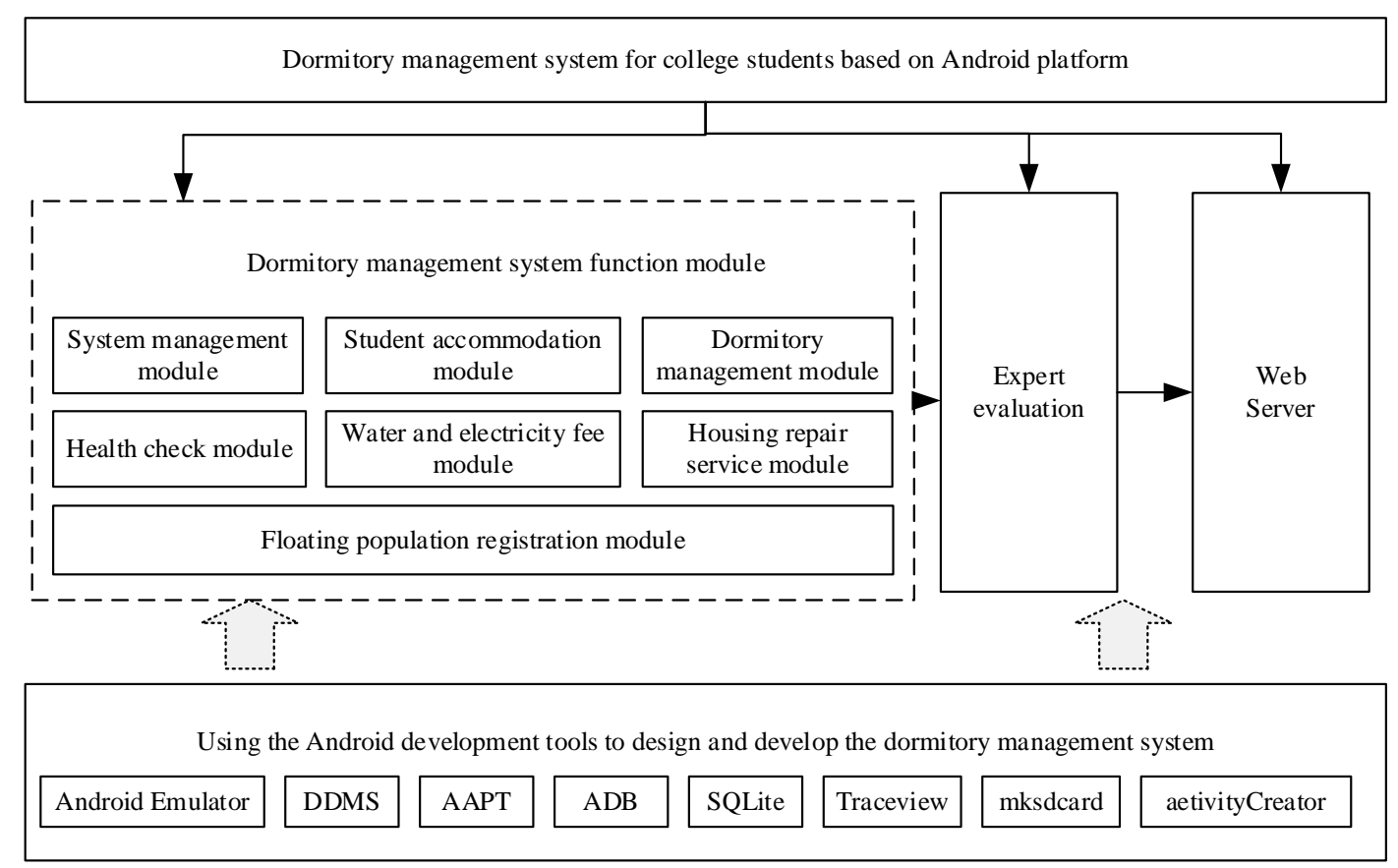

Figure 3.The college student dormitory management system based on Android

\section{Conclusion}

In the Internet technology has been increasingly mature today, in order to improve the work efficiency of school staff dormitory management, better help dormitory administrator for the intelligent student dormitory management, a high performance of students' dormitory management information system is particularly important. It can provide efficient and convenient query channel for students, but also for the school dormitory administrator timely understanding of students' dormitory information, which can make the corresponding work in a timely manner and tactical adjustment, so that the students can improve the satisfaction of the dormitory administrator. This paper used the Android platform, not only takes advantage of the existing school digital campus network, but also make the system operation more humanized and simplicity, but also improve the maintainability of the system.

\section{References}

[1] WANG X, XU W. Design and Implementation of Construction Material Rental Leasing Information Management System Based on Web Service[J]. Computer and Information Technology, 2012, 3: 018.

[2] Y. TAO, Z. WU, D. TANG: Computer Engineering and Design, Vol. 4(2010), p.25.

[3 T. Parsons, A. Mos, J. Murphy: IEE Proceedings-Software, Vol. 153(20011) No.4, p. 149

[4] K. Laufer: Computing in Science \& Engineering, Vol. 7(2009) No.5, p. 80.

[5] Pan J, Jain R, Biswas P, et al. A framework for smart location-based automated energy controls in a green building testbed[C]//Energytech, 2012 IEEE. IEEE, 2012: 1-6.. 